BMJ Open

Diabetes

Research

\& Care

\section{Flash glucose monitoring in type 2 diabetes managed with basal insulin in the USA: a retrospective real-world chart review study and meta-analysis}

To cite: Carlson AL, Daniel TD, DeSantis A, et al. Flash glucose monitoring in type 2 diabetes managed with basal insulin in the USA: a retrospective realworld chart review study and meta-analysis. BMJ Open Diab Res Care 2022;10:e002590. doi:10.1136/

bmjdrc-2021-002590

- Additional supplemental material is published online only. To view, please visit the journal online (http://dx.doi. org/10.1136/bmjdrc-2021002590).

Received 9 September 2021 Accepted 10 December 2021

Check for updates

(C) Author(s) (or their employer(s)) 2022. Re-use permitted under CC BY-NC. No commercial re-use. See rights and permissions. Published by BMJ.

For numbered affiliations see end of article.

Correspondence to Dr Anders L Carlson; Anders.L.Carlson@ HealthPartners.Com

\section{ABSTRACT}

Introduction Evidence supporting use of continuous glucose monitoring in type 2 diabetes treated with basal insulin is unclear. This real-world study aimed to assess the impact on glycated hemoglobin (HbA1c) of flash glucose monitoring use in adults with type 2 diabetes managed with basal insulin.

Research design and methods Medical records were reviewed for adult individuals with type 2 diabetes using basal insulin for $\geq 1$ year with or without additional antihyperglycemic medication, $\mathrm{HbA} 1 \mathrm{c} 8.0 \%-12.0 \%$ prior to FreeStyle Libre Flash Glucose Monitoring use for $\geq 90$ days and an $\mathrm{HbA1c}$ measurement recorded between 90 and 194 days after device use. Exclusion criteria included utilization of bolus insulin. Meta-analysis data are from the current study (USA) and a similar Canadian cohort. Results Medical record analysis $(n=100)$ from 8 USA study sites showed significant $\mathrm{HbA} 1 \mathrm{c}$ decrease of $1.4 \% \pm 1.3 \%$, from $9.4 \% \pm 1.0 \%$ at baseline to $8.0 \% \pm 1.2 \%$ after device use, $p<0.0001$ (mean $\pm S D$ ).

Meta-analysis of medical records from USA and Canada sites $(n=191)$ showed HbA1c significantly decreased by $1.1 \% \pm 0.14 \%($ mean \pm SE), from baseline $9.2 \% \pm 1.0 \%$ to $8.1 \% \pm 1.1 \%, p \leq 0.0001$, with moderate to high heterogeneity between sites $\left(Q=43.9, I^{2}=74.9, p<0.0001\right)$ explained by differences in baseline $\mathrm{HbA1c}$ between sites. The HbA1c improvement in both groups was observed by age group, body mass index, duration of insulin use and sex at birth.

Conclusions In a real-world retrospective USA study and a meta-analysis of a larger USA and Canada cohort, $\mathrm{HbA1c}$ significantly reduced in basal insulin-treated type 2 diabetes, without bolus insulin initiation and following the commencement of flash glucose monitoring technology.

\section{INTRODUCTION}

The American Diabetes Association (ADA) recognizes that glycemic management is primarily assessed by glycated hemoglobin (HbA1c) measurements. ${ }^{1}$ HbAlc has been the principal clinical marker used in clinical trials to demonstrate the benefits of improved glycemic management. ${ }^{1}$ In regard to continuous glucose monitoring (CGM), the ADA acknowledges that this technology has an

\section{Significance of this study}

What is already known about this subject?

- To date, the reported benefit of continuous glucose monitoring (CGM) use in type 2 diabetes is largely limited to intensive insulin regimens.

- Evidence supporting use of this type of glucose monitoring technology to support management of a basal insulin regimen is limited.

What are the new findings?

In this real-world observational review study in the USA and meta-analysis of a larger USA and Canada cohort:

- Glycated hemoglobin (HbA1c) significantly reduced in both groups 3-6 months after commencing flash glucose monitoring technology use in type 2 diabetes treated with basal insulin and without initiating bolus insulin.

- $\mathrm{HbA1C}$ reduction is supported by the sensitivity analysis demonstrating consistent $\mathrm{HbA} 1 \mathrm{c}$ values.

- HbA1c improvement was observed in both groups by age group, body mass index, duration of insulin use and sex at birth; over half of the participants had a final $\mathrm{HbA} 1 \mathrm{C}<8 \%$.

\section{How might these results change the focus of} research or clinical practice?

- HbA1C is the gold standard clinical marker used to demonstrate improved glycemic control.

- This finding may suggest that the use of CGM in type 2 diabetes treated with basal insulin has the potential to be a valuable tool to support the improvement of glucose control.

important role in glucose management for diabetes and notes that the reported benefit of CGM in type 2 diabetes is to date largely limited to its use with intensive insulin regimens. ${ }^{2}$ While there is increasing evidence to support CGM use in this population, ${ }^{3-6}$ reported evidence of CGM use to support management of a basal insulin regimen is more limited. ${ }^{7-11}$ The aim of this real-world study was to evaluate the impact on HbAlc 
after the introduction of flash glucose monitoring use in type 2 diabetes managed with basal insulin in diabetes centers in the USA. Analysis of a larger cohort combining data from the USA and Canada is also reported.

\section{MATERIALS AND METHODS}

The methodology and population of the current study are analogous to those described by Elliott et al. ${ }^{10}$ The current retrospective non-interventional single-arm chart review study was conducted in diabetes centers in the USA. The clinics each performed a database search for potential medical records to be included in the review. Paper or electronic medical records were included for adult individuals (18 years or more) with type 2 diabetes managed with analogue or isophane basal insulin therapy for 1 year or more, with or without additional oral antihyperglycemic medication and non-insulin injection therapy, the FreeStyle Libre Flash Glucose Monitoring System (Abbott Diabetes Care, Alameda, California, USA) had been used for at least 90 days when the data were collected, an HbAlc measurement between $8.0 \%$ and $12.0 \%$ was recorded in the medical notes within 90 days before device use commenced and an HbAlc measurement was recorded $>90$ and $<194$ days after initiation of device use. The definition of a baseline HbAlc was a result recorded not more than 90 days before device use commenced (the index date). If additional baseline HbAlc measurements were available, the one nearest to the index date was used. The definition of a follow-up HbA1c measurement was a result recorded not less than 90 and no more than 194 days after the index date. If additional follow-up HbA1c measurements were available, the measurement closest to the index date plus 135 days was used. All HbAlc measurements used in the analysis had been recorded in the medical records and were from a laboratory or point-of-care test. In addition to baseline HbAlc concentrations, the study sites also extracted information that had been recorded in the medical records prior to initiation of device use for age, blood pressure, concomitant disease, complications of diabetes, time using insulin, height, glucose-lowering medications, sex and weight.

Medical records were not eligible for inclusion in the study for anyone who was using bolus or biphasic insulin, pregnant, undergoing dialysis therapy or was a participant in another study that might impact their glucose results or management during use of the device.

Analysis of the extracted data from the medical records established final eligibility for inclusion in the analysis.

Additional data for the meta-analysis were from a retrospective non-interventional single-arm chart review study in Canada, as noted above. ${ }^{10}$

\section{Outcomes}

The primary end point for the current study and the meta-analysis was evaluation of change in $\mathrm{HbAlc}$ from the index date to a follow-up HbAlc measurement taken after device use was commenced (between 90 and 194 days after). Analysis of the primary end point was also performed for the subgroups: age $(<65$ and $\geq 65$ years), HbA1c at baseline $(<9 \%$ and $\geq 9 \%)$, body mass index (BMI $\left(<30\right.$ and $\left.\left.\geq 30 \mathrm{~kg} / \mathrm{m}^{2}\right)\right)$, duration of insulin use $(<4$ and $\geq 4$ years), rate of daily blood glucose testing and sex at birth. As this was a retrospective chart review study, safety and adverse event information were not collected.

\section{Statistical analysis}

A paired t-test was used to assess differences between HbA1c measurements recorded 90 to 194 days after starting device use and at baseline. A total of 78 medical records are needed to detect a change in HbA1c of $0.35 \%(3.8 \mathrm{mmol} / \mathrm{mol})$ within each country with a power of $80 \%$ (at $\mathrm{p}<0.05$ ), based on an SD of change in HbA1c of $1.1 \%{ }^{12}$ For the primary end point, if more than one HbAlc test fulfilled the criteria then the test nearest to the device start date +135 days was used. Meta-analysis of change in $\mathrm{HbAlc}$ was performed using a random effects model on patient record level data, using center as a random effect. Cochran's heterogeneity statistic $(Q)$ and the $I^{2}$ statistic were calculated. ${ }^{13}$ A meta-regression analysis was performed on baseline HbAlc with center as a random effect. Subgroups were compared using analysis of covariance on baseline HbAlc. Qualified statisticians at Abbott Diabetes Care (UK) performed the data analysis using V.9.4 of SAS (or higher).

\section{RESULTS}

The USA chart review data were extracted from medical records between November 2017 and July 2020. A total of 131 medical records from both primary care (Internal Medicine and Family Practice) and more specialist diabetes centers were identified by 8 study sites. Of these, 11 did not meet the inclusion criteria, 6 had a baseline HbAlc outside the stated range of $8.0 \%-12.0 \%$, 3 had not used basal insulin for at least 1 year prior to starting device use (or the duration was unknown) and 2 had bolus insulin therapy use recorded. In addition, 6 medical records did not have a baseline $\mathrm{HbA1c}$ within 90 days of starting device use, 12 medical records did not have a HbA1c result logged between 90 and 194 days after starting to use the device and 2 medical records had neither a baseline nor a final HbAlc result. The total number of medical records included in the USA primary end point analysis was 100 .

The mean age at the start of device use was $56.0 \pm 10.3$ years $($ mean $\pm \mathrm{SD})$, baseline HbA1c was $9.4 \% \pm 1.0 \%$ and $52(52 \%)$ of medical records were for male individuals.

For the meta-analysis, a total of 234 medical records were identified by 14 study sites in the USA $(n=8)$ and Canada $(n=6)$ from November 2017 to July 2020. Fourteen medical records did not meet the eligibility criteria, 9 did not have a baseline HbA1c within 90 days of starting the device, 14 did not have an HbAlc result 90-194 days after starting the device and 3 did not have a baseline 
Table 1 Demographics and baseline characteristics for the US and combined cohorts

\begin{tabular}{|c|c|c|c|}
\hline \multirow{2}{*}{$\mathbf{N}$} & & \multirow{2}{*}{$\begin{array}{l}\text { US cohort } \\
n=100\end{array}$} & \multirow{2}{*}{$\begin{array}{l}\text { Combined group cohort } \\
\mathrm{n}=191\end{array}$} \\
\hline & & & \\
\hline Male n (\%) & & $52(52.0)$ & $115(60.2)$ \\
\hline Female n (\%) & & $48(48.0)$ & $76(39.8)$ \\
\hline Age (years) & Mean \pm SD & $56.0 \pm 10.3$ & $60.0 \pm 11.3$ \\
\hline BMI $\left(\mathrm{kg} / \mathrm{m}^{2}\right)$ & Mean \pm SD & $36.1 \pm 7.8(n=97)$ & $33.5 \pm 8.2(n=184)$ \\
\hline Duration of insulin use (years) & Mean \pm SD & $4.5 \pm 3.5$ & $4.3 \pm 3.3$ \\
\hline Baseline HbA1c (\%) & Mean $\pm S D$ & $9.4 \pm 1.0$ & $9.2 \pm 1.0$ \\
\hline Baseline $\mathrm{HbA} 1 \mathrm{c}(\mathrm{mmol} / \mathrm{mol})$ & Mean \pm SD & $79.2 \pm 11.1$ & $76.8 \pm 10.7$ \\
\hline \multirow{7}{*}{$\begin{array}{l}\text { Additional antihyperglycemic } \\
\text { medications at time of starting flash } \\
\text { glucose monitoring, } \mathrm{n}(\%)\end{array}$} & Any oral antihyperglycemic medication & $96(96.0)$ & $183(95.8)$ \\
\hline & Metformin & $82(82.0)$ & $151(79.1)$ \\
\hline & SGLT inhibitors & $28(28.0)$ & $85(44.5)$ \\
\hline & Sulfonylureas & $40(40.0)$ & $70(36.6)$ \\
\hline & DPP4 inhibitors & $11(11.0)$ & $46(24.1)$ \\
\hline & Thiazolidinediones & $4(4.0)$ & $5(2.6)$ \\
\hline & GLP1 agonists & $56(56.0)$ & $100(52.4)$ \\
\hline
\end{tabular}

BMI, body mass index; DPP4, dipeptidyl peptidase-4; GLP1, glucagon-like peptide-1 receptor; HbA1c, glycated hemoglobin; SGLT, sodium-glucose cotransporter.

nor a final HbA1c result. Three records were retrospectively excluded as bolus insulin was used during the study period. The total number of medical records included in the meta-analysis was 191.

For the USA and Canda combined cohort, the mean age at start of device use was $60.0 \pm 11.3$ years $($ mean $\pm \mathrm{SD})$, baseline HbAlc was $9.2 \% \pm 1.0 \%$ and 115 (60.2\%) medical records were for male individuals. Baseline characteristics and demographics, and medical history from the medical records for both the USA cohort and the combined USA and Canada cohort are listed in tables 1 and 2 , respectively.

Baseline characteristics for the Canada-only cohort are listed in online supplemental table S2.

\section{Primary end point}

In the current USA study, baseline HbAlc (mean \pm SD) significantly reduced between 90 and 194 days after starting device use by $1.4 \% \pm 1.3 \%$ from $9.4 \% \pm 1.0 \%$ to $8.0 \% \pm 1.2 \%, \mathrm{p}<0.0001$ (figure 1 and online supplemental table $\mathrm{S} 1$ ).

In the meta-analysis of combined USA and Canada data, baseline HbA1c significantly reduced 90-194 days after starting device use by $1.1 \% \pm 0.14 \%$ (mean \pm SE) from $9.2 \% \pm 1.0 \%$ to $8.1 \% \pm 1.1 \% \quad($ mean $\pm S D), p \leq 0.0001$ (figure 1 and online supplemental table S1). Moderate to high heterogeneity between centers $\left(\mathrm{Q}=43.9, \mathrm{I}^{2}=74.9 \%\right.$, $\mathrm{p}<0.0001$ ) was observed.

The meta-regression of change in HbAlc on baseline HbAlc showed a slope of $-0.66 \% \pm 0.078 \%$ per $\%$ baseline HbA1c $($ mean $\pm \mathrm{SE})$ and low heterogeneity with an $\mathrm{I}^{2}$ value of $1.6 \%$ (Cochran's $Q=10.2, p=0.4267$ ).

\section{Sensitivity analysis}

For the USA cohort, the mean number of days between initiation of device use (index date) and the final HbAlc value used in the analysis was 131.7 days (median 132.0). A sensitivity analysis was performed on the primary end point of change in $\mathrm{HbAlc}$ for different time windows of the final HbA1c value (121-149 days, 107-163 days and 90-180 days) and the change in HbA1c remained similar $(p<0.0001$ for all time windows, figure 2$)$.

When baseline HbAlc measurements were compared with follow-up HbA1c measurements for each month of the 3-6 months period after device use was initiated (months 3-4, 4-5, 5-6 and 5.5-6.5), HbAlc change remained significant (figure 2 ).

\section{Subgroup analysis}

For the current USA study and the larger cohort of both countries combined, prespecified subgroup analysis showed HbA1c improvement by age group $(<65$ and $\geq 65$ years), baseline HbAlc $(<9 \%$ and $\geq 9 \%)$, BMI $(<30$ and $\left.\geq 30 \mathrm{~kg} / \mathrm{m}^{2}\right)$, duration of insulin use $(<4$ and $\geq 4$ years $)$ and sex at birth.

In the 2 countries combined cohort, there was a similar change in $\mathrm{HbA1c}$ between the subgroups for age $(\mathrm{p}=0.0900)$, BMI $(\mathrm{p}=0.2811)$, duration of insulin use $(p=0.4057)$, blood glucose testing frequency $(p=0.1495)$ or sex at birth $(\mathrm{p}=0.6966)$. All subgroup analysis results are shown in figure 3 .

In the current USA study, recorded data for frequency of self-monitoring of blood glucose (prior to flash glucose monitoring use) were available from $55 \%(n=55 / 100)$ of the US medical records and $56 \%(\mathrm{n}=107 / 191)$ of the USA and Canada group medical records (online supplemental table S1). 
Table 2 Medical history at baseline for the US and combined cohorts

\begin{tabular}{|c|c|c|}
\hline & US cohort & $\begin{array}{l}\text { Combined } \\
\text { group cohort }\end{array}$ \\
\hline N (\%) & $n=100$ & $n=191$ \\
\hline CVD complications & $19(19.0)$ & $54(28.3)$ \\
\hline Myocardial infarction & $4(4.0)$ & $16(8.4)$ \\
\hline Angina & $6(6.0)$ & $25(13.1)$ \\
\hline Peripheral vascular disease & $6(6.0)$ & $11(5.8)$ \\
\hline Stroke & $4(4.0)$ & $9(4.7)$ \\
\hline Heart failure & $3(3.0)$ & $6(3.1)$ \\
\hline Atrial fibrillation & $0(0.0)$ & $5(2.6)$ \\
\hline Left ventricular hypertrophy & $1(1.0)$ & $10(5.2)$ \\
\hline Renal complications & $13(13.0)$ & $60(31.4)$ \\
\hline Microalbuminuria & $12(12.0)$ & $57(29.8)$ \\
\hline Gross proteinuria & $2(2.0)$ & $7(3.7)$ \\
\hline End-stage renal disease & $1(1.0)$ & $1(0.5)$ \\
\hline Retinopathy complications & $15(15.0)$ & $27(14.1)$ \\
\hline $\begin{array}{l}\text { Background diabetic } \\
\text { retinopathy }\end{array}$ & $13(13.0)$ & $22(11.5)$ \\
\hline $\begin{array}{l}\text { Proliferative diabetic } \\
\text { retinopathy }\end{array}$ & $3(3.0)$ & $5(2.6)$ \\
\hline Severe vision loss & $0(0.0)$ & $1(0.5)$ \\
\hline Foot ulcer Complications & $2(2.0)$ & $5(2.6)$ \\
\hline Uninfected ulcer & $0(0.0)$ & $1(0.5)$ \\
\hline Infected ulcer & $0(0.0)$ & $1(0.5)$ \\
\hline Healed ulcer & $2(2.0)$ & $4(2.1)$ \\
\hline Amputation & $0(0.0)$ & $1(0.5)$ \\
\hline Cataract & $10(10.0)$ & $30(15.7)$ \\
\hline Macular oedema & $5(5.0)$ & $5(2.6)$ \\
\hline Neuropathy & 17 (17.0) & 35 (18.3) \\
\hline Depression & $23(23.0)$ & 35 (18.3) \\
\hline
\end{tabular}

CVD, cardiovascular disease.

The majority of this subgroup reported testing twice per day or less $(n=42 / 55$ and $n=89 / 107$, respectively). Baseline HbAlc reduced by $1.4 \% \pm 1.0 \%$ and $1.2 \% \pm 1.1 \%$ $($ mean \pm SD), respectively, $\mathrm{p}<0.0001$ for both groups. For more than 2 tests per day $(\mathrm{n}=13$ and $\mathrm{n}=18)$, baseline HbA1c fell by $0.9 \% \pm 1.5 \%(\mathrm{p}=0.0579)$ in the USA group and by $1.0 \% \pm 1.5 \%(\mathrm{p}=0.0104)$ in the larger USA and Canada group.

Post hoc analysis demonstrated $56 \%(\mathrm{n}=56 / 100)$ of USA participants had a final HbAlc $<8 \%$.

\section{DISCUSSION}

This USA retrospective chart review clinical study observed significant improvement in HbAlc 3-6 months after use of flash glucose sensor monitoring technology was commenced in individuals with type 2 diabetes managed with basal insulin. Bolus insulin initiation and use were not permitted either before or during the study. The unequivocal achievement of the primary end point

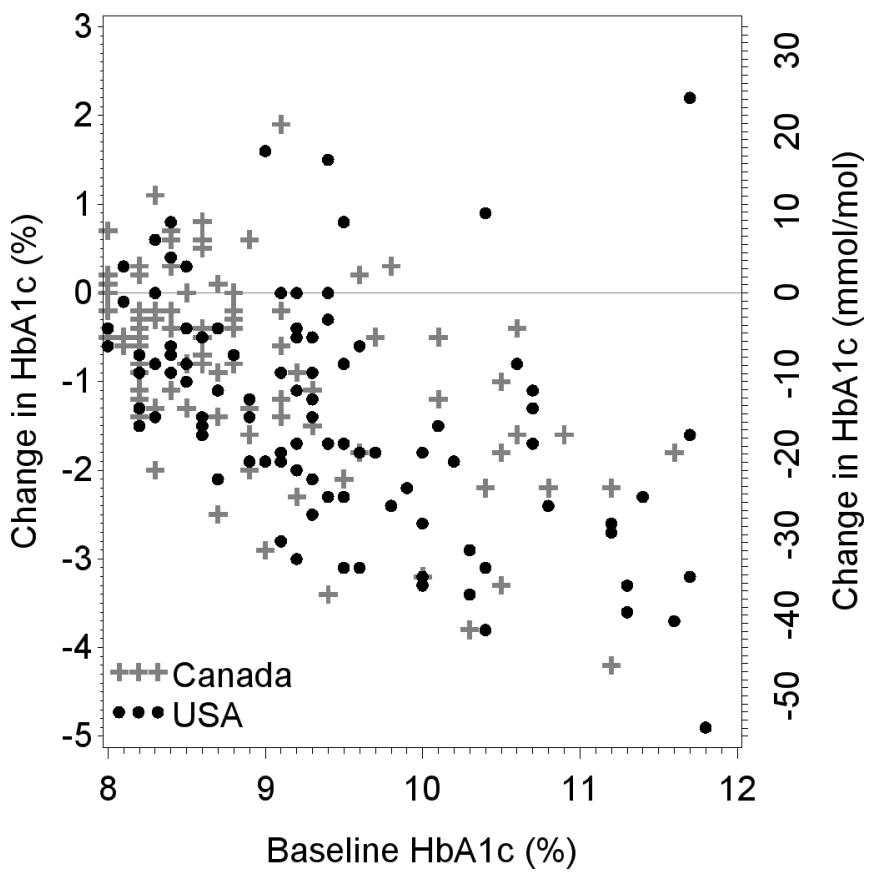

Figure 1 Change in glycated hemoglobin (HbA1c) (\%) between baseline and at 3-6 months (90-194 days) after commencing flash glucose monitoring.

is supported by the observed HbAlc reduction in the larger meta-analysis cohort and the sensitivity analysis demonstrating consistent $\mathrm{HbA1c}$ values, which was also reported separately for the Canada cohort. ${ }^{10}$

The observed significant decrease in HbA1c in the USA cohort is supported by an earlier prospective randomized controlled trial in intermittent use of real-time CGM in

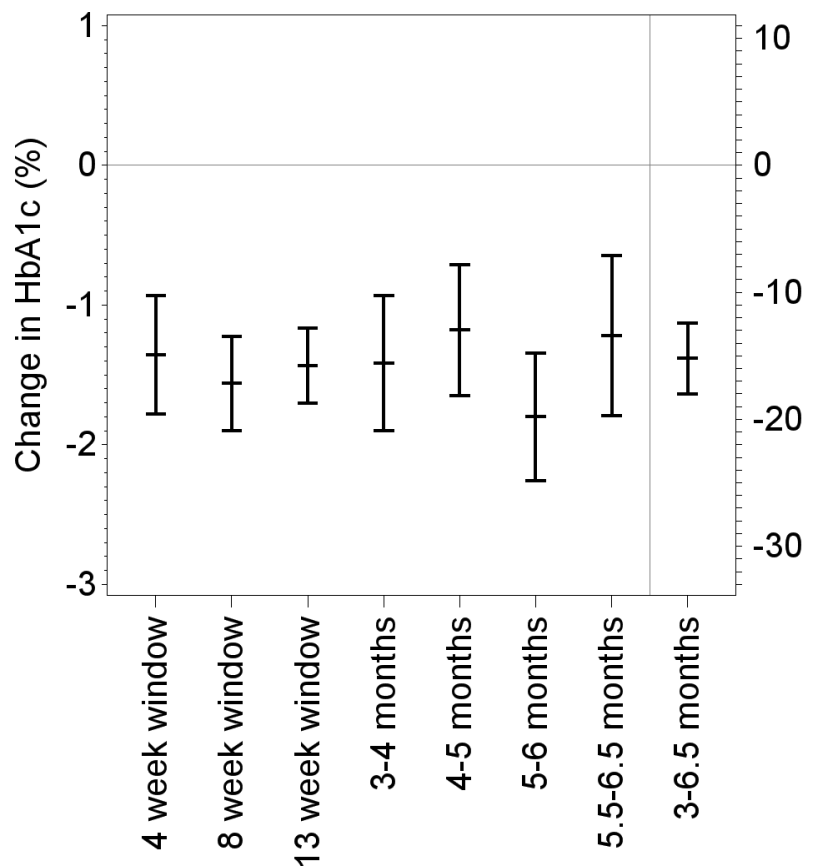

Figure $2 \mathrm{Cl}$ plot of change in glycated hemoglobin ( $\mathrm{HbA1c}$ ) (\%) with narrower time windows around day 135 and change in $\mathrm{HbA1c}(\%)$ for each month of the 3-6 months after commencing flash glucose monitoring for the US cohort. 


\section{A}

Mean and $95 \% \mathrm{Cl}$ for Change in $\mathrm{HbA} 1 \mathrm{c}(\mathrm{mmol} / \mathrm{mol})$

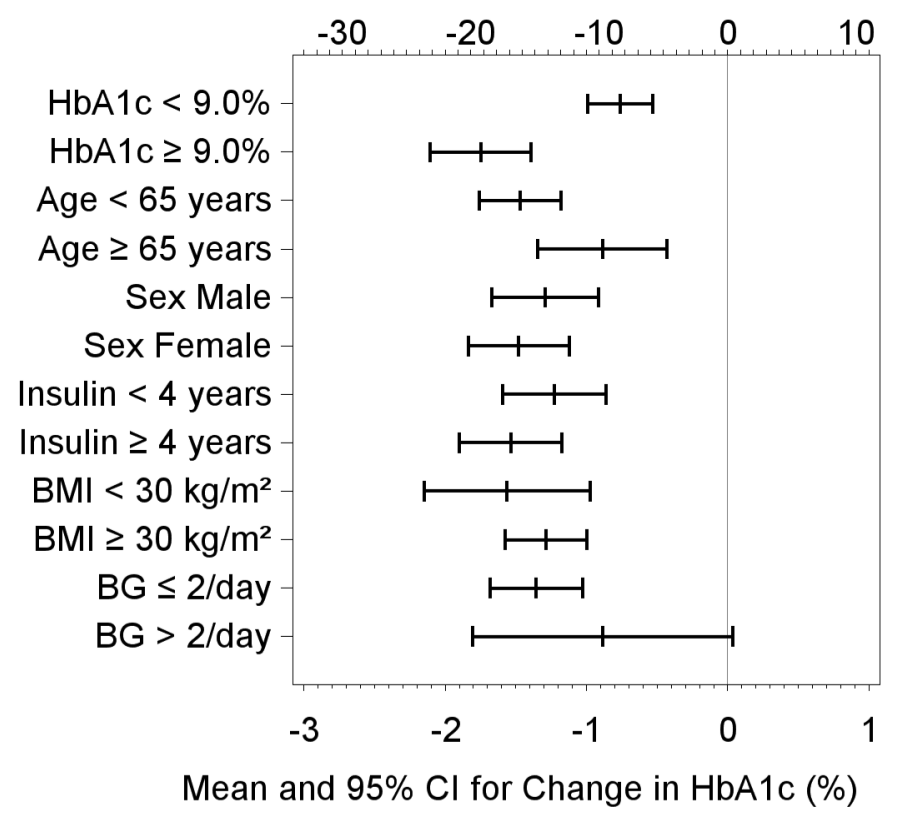

B

Mean and $95 \% \mathrm{Cl}$ for Change in $\mathrm{HbA} 1 \mathrm{c}(\mathrm{mmol} / \mathrm{mol})$

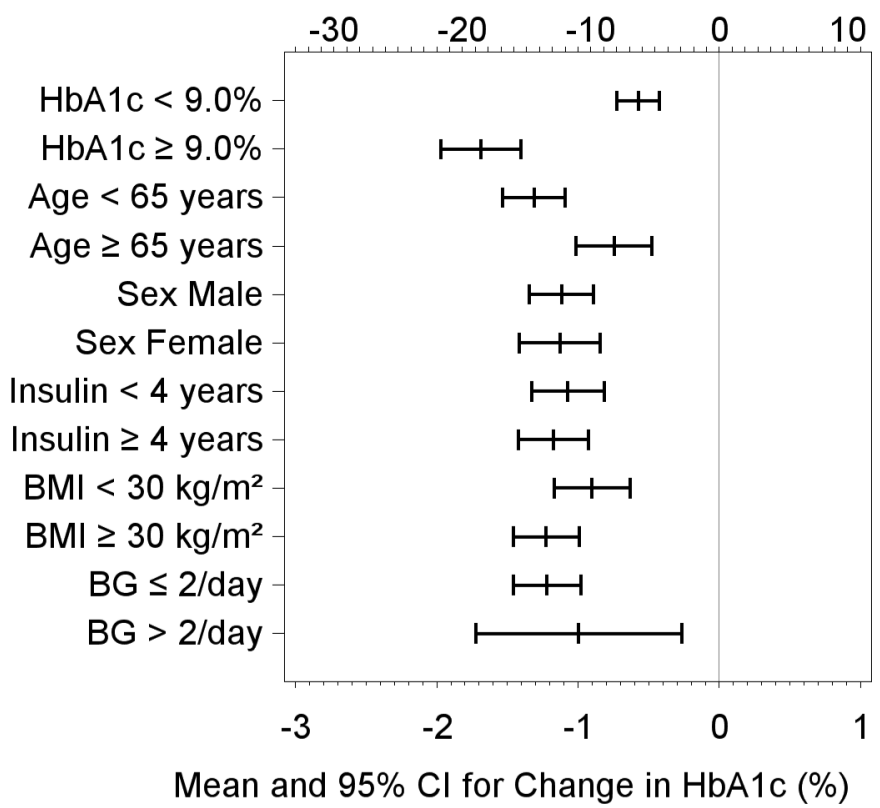

Figure 3 Change in glycated hemoglobin (HbA1c) by baseline $\mathrm{HbA} 1 \mathrm{c}$, age, sex at birth, duration of insulin use, body mass index (BMI) and blood glucose (BG) testing frequency for the US cohort (A) and the combined group cohort (B).

a type 2 diabetes cohort using either basal insulin and/ or antihyperglycemic medications, which demonstrated a $1.2 \%$ (within group) HbA1c reduction after 6 months. ${ }^{7}$ In this mixed cohort, the majority of these participants were non-insulin users who may show a more pronounced change in $\mathrm{HbAlc}$ with CGM. ${ }^{9}$ However, a recent randomized controlled trial in a similar cohort to the current study reported a comparable within-group $\mathrm{HbA1c}$ reduction at 8 months in the CGM group. ${ }^{11}$

The current chart review study supports reported findings by studies in flash glucose monitoring with a similar population and methodology from Canada $(0.8 \%)^{10}$ and the USA $(0.6 \%) .{ }^{9}$ In 2021 , Wright et al reported a $1.1 \%$ reduction in type 2 diabetes managed with basal insulin therapy and flash glucose monitoring use. ${ }^{8}$ The observed reduction in HbAlc in the current study is consistent with other studies in flash glucose monitoring and CGM in type 2 diabetes with multiple insulin injection therapy (MDI), which have demonstrated HbAlc reductions of $0.8 \%-0.9 \% .^{4-6}$

The current meta-analysis of the larger USA and Canada combined cohort adds to other recent meta-analyses. These included randomized controlled trials and showed an overall improvement in HbA1c of $0.26 \%-0.56 \%$ in adults with diabetes using flash glucose monitoring and $0.42 \%$ in type 2 diabetes only. ${ }^{14} 15$ The meta-analysis from Castellana $e a^{15}$ found that a $0.4 \%$ decrease in HbAlc was associated with each $1 \%$ increase in baseline levels over $7.2 \%$, which correlates with the observed improvement in HbA1c. ${ }^{14}$ The observed moderate to high heterogeneity was likely due to differences in the baseline HbAlc measurements between centers.
Significant change in HbAlc was demonstrated in the current study and the meta-analysis data sets regardless of age group (figure 3 and online supplemental table S1). The REPLACE (Flash Glucose-Sensing Technology as a Replacement for Blood Glucose Monitoring for the Management of Insulin-Treated Type 2 Diabetes) study, a randomized controlled study in use of this monitoring technology and type 2 diabetes managed with MDI, demonstrated a decrease in $\mathrm{HbAlc}$ only in individuals $<65$ years of age. ${ }^{3}$ Haak $e t a l^{3}$ speculated that a more cautious approach to therapy adjustments in the older participants due to the risk of hypoglycemia may have been a factor. The finding in the current studies for the age subgroups contrasts with this and supports recent studies showing benefit from use of this technology irrespective of age in individuals with type 2 diabetes managed with MDI. ${ }^{56}$

The observed change in HbAlc was more marked for HbA1c levels $>9 \%$. A greater reduction in HbA1c from a higher baseline measurement has been observed in other studies in flash glucose monitoring and type 2 diabetes managed with either insulin or non-insulin therapies. ${ }^{568}$

At baseline, the most common oral antihyperglycemic medication used with basal insulin was metformin followed by a sulfonylurea for the USA cohort and a sodium-glucose cotransporter (SGLT) inhibitor in the Canada cohort. The use of SGLTs inhibitors in the USA cohort (28\%) was similar to a report of national prescribing trends ${ }^{16}$ and lower than in the Canada cohort (62\%). Dipeptidyl peptidase-4 (DPP4) inhibitor prescribing was also lower in the USA group (11\%) than the Canada group (39\%) and compared with national prescribing trends. ${ }^{17}$ Use of glucagon-like peptide-1 
receptor agonists (GLP1 agonists) was similar in both countries as was the low use of thiazolidinedione therapy reflecting the overall decreasing trend for prescribing this medication. ${ }^{18}$ Details of antihyperglycemic medications for the Canada-only cohort are listed in online supplemental table S2.

The baseline medical history and the prevalence of cardiovascular disease, angina and stroke, depression and renal disease in the current study (table 2) are broadly similar to other studies in this population. ${ }^{6}{ }^{17}{ }^{19}$ Baseline demographics and characteristic data for age and use of basal insulin were also typical of patients with type 2 diabetes. ${ }^{70-22}$ Mean baseline HbA1c at $9.4 \%$ confirms a trend for therapeutic inertia and general tolerance of suboptimal glycemic control in type 2 diabetes. ${ }^{23}{ }^{24}$ Mean BMI was $>30 \mathrm{~kg} / \mathrm{m}^{2}$ in the current study reflecting the high prevalence of obesity in the USA and its association with type 2 diabetes. ${ }^{21} 2526$

Achieving glycemic targets in type 2 diabetes remains one of the key goals of diabetes management. Review of glucose control and titration of basal-only insulin therapy is generally supported by an HbA1c measurement and blood glucose testing results. ${ }^{1}$ The optimum frequency of self-monitoring in this population is imprecise. In the present study and the meta-analysis, the majority of medical records showed a daily testing frequency of 2 tests or less per day. This minimal utilization of fingerstick glucose monitoring by an individual does not appear to automatically influence HbA1c reduction with flash glucose monitoring use. ${ }^{610}$

\section{Study strengths and limitations}

A limitation of this study is the single-arm retrospective chart review methodology which, by definition, precludes a control group. Recent randomized controlled trials in CGM and type 2 diabetes managed with either MDI or basal insulin therapy reported change in HbAlc in the control arm of up to $0.6 \% .^{4511}$ Speculatively, if this indicates potential study effect, the observed change in HbAlc would remain clinically relevant in the present study and meta-analysis.

The methodology prevented more individualized data collection and although bolus insulin use was excluded before and during the data collection period, the potential impact of any additional oral medications is unknown. Therefore, the observed $\mathrm{HbA1c}$ reduction following initiation of flash monitoring may be due to a combination of different factors. Basal insulin dose titration, oral medication adjustments, clinical contact and behavior or lifestyle modifications, supported by device use, likely all contributed to achieving the primary end point. The use of glucose reports, such as the ambulatory glucose profile, as an educational resource for clinicians and patients to use together at review visits has been reported by prospective studies in flash glucose monitoring use in type 2 diabetes. ${ }^{3} 27$ Correspondingly, a strength of the study's retrospective, pragmatic methodology is the lack of mandated glucose management or study administration during clinical interactions resulting in negligible impact on selection for study inclusion and clinical care during the study. These factors, together with the participant demographics and characteristics, which are typical of the individuals with type 2 diabetes, suggest the observed finding may be generalized and applied in other clinical settings. The length of the current study is potentially a limitation as the observed change in HbA1c may not be sustained after 6 months. However, the breakdown for change in HbAlc for each month after a minimum of 3-6 months use of this technology suggests that the change is durable. Vigersky et al reported that $\mathrm{HbA} 1 \mathrm{c}$ reduction following intermittent CGM use in a mixed cohort of type 2 diabetes managed with basal insulin or non-insulin therapies was significant at 12 months. ${ }^{7}$ More recently, Miller et al reported HbAlc improvement was sustained at 12 months in type 2 diabetes managed with basal insulin and using flash glucose monitoring. ${ }^{9}$

The current study and meta-analysis add to the growing evidence for use of this technology in type 2 diabetes. Bolus insulin was not initiated during the study and the observed improvement in HbAlc is comparable to the expected impact on glucose control from basal insulin initiation in insulin-naïe type 2 diabetes. ${ }^{21}$ However, it should also be acknowledged that despite the pronounced change in the HbAlc level, it remained above the ADA recommended target for this cohort. ${ }^{1}$ As an HbAlc level of $>8 \%$ is an indication of basal and postprandial hyperglycemia, ${ }^{28}$ further studies in management of type 2 diabetes with all therapies and CGM technology are warranted. ${ }^{11}$

\section{CONCLUSION}

In conclusion, significantly reduced $\mathrm{HbAlc}$ was retrospectively observed following commencement of flash glucose monitoring technology in type 2 diabetes treated with basal insulin and without prandial insulin use.

Author affiliations

${ }^{1}$ International Diabetes Centre IDC, HealthPartners Institute, Minneapolis, Minnesota, USA

${ }^{2}$ Diabetes Wellness Clinic, Pearland, Texas, USA

${ }^{3}$ Department of Family Medicine, The Charlotte-Mecklenburg Hospital Authority d/b/a Atrium Health, Charlotte, North Carolina, USA

${ }^{4}$ Diabetes Research Center, Thomas Jefferson University, Philadelphia, Pennsylvania, USA

${ }^{5}$ Department of Endocrinology, University of Pittsburgh Medical Center, Pittsburgh, Pennsylvania, USA

${ }^{6}$ Division of Endocrinology, Henry Ford Health System, Detroit, Michigan, USA

${ }^{7}$ Diabetes and Obesity Care LLC, Bend, Oregon, USA

${ }^{8}$ Texas Diabetes \& Endocrinology, Round Rock, Texas, USA

${ }^{9} \mathrm{BC}$ Diabetes, Vancouver, British Columbia, Canada

Acknowledgements The authors thank all those who contributed to the collection of data at the study sites: International Diabetes Center IDC, HealthPartners Institute, Minneapolis, Minnesota; Diabetes Wellness Clinic, Pearland, Texas; The Charlotte-Mecklenburg Hospital Authority d/b/a Atrium Health, Charlotte, North Carolina; Thomas Jefferson University, Diabetes Research Center, Philadelphia, 
Pennsylvania; University of Pittsburgh Medical Center, Pittsburgh, Pennsylvania; Henry Ford Health System, Division of Endocrinology, Diabetes, Detroit, Michigan; Diabetes and Obesity Care, Bend, Oregon; Texas Diabetes \& Endocrinology, Round Rock, Texas and BC Diabetes, Vancouver, British Columbia, Canada. In addition, the authors thank Marcus Green and Zoe Welsh for statistical support (Statistics, Abbott Diabetes Care, UK) and Amanda Cartmale (Scientific Affairs Manager, Abbott Diabetes Care, UK) for editorial support during manuscript preparation.

Contributors All named authors have contributed towards writing, reviewing and revising the manuscript, meet the International Committee of Medical Journal Editors (ICMJE) criteria for authorship, assume responsibility and accountability for the results, and have given their approval for this version to be published. ALC, as the guarantor, accepts full responsibility for the work and the conduct of the study, had access to the data, and controlled the decision to publish.

Funding In collaboration with the chief investigator, Abbott, Diabetes Care designed the study protocol. Abbott, Diabetes Care provided all study materials and was involved in data analysis and reporting. Abbott, Diabetes Care did not participate in the authors' interpretation of the study results. All authors had full access to all of the data in the study and take full responsibility for the integrity of the data and the accuracy of its analysis.

Competing interests ALC received research support, acted as a consultant or served on a scientific advisory board for Abbott Diabetes, Dexcom, Eli Lilly, Insulet, Medtronic, Novo Nordisk, Sanofi, Senseonics and United Healthcare, but did not receive any personal income. ALC is on the Board of Directors, JDRF Minnesota and Dakota chapter. TDD has served on a scientific advisory board for Abbott Diabetes. The healthcare system that ADeS works for receives research funding, but that money is not part of her current compensation arrangement, nor does she receive additional personal income. SJ, EKF and EM declare no relevant or materia financial interests relating to the research described in this paper. DK has received research support and acted as a consultant for Abbott Diabetes. KO received research support from Abbott Diabetes but did not receive any personal income. KO received grants or served on a scientific advisory board for Eli Lilly, Novo Nordisk and Sanofi. KO is President of the Texas AACE chapter. TE has participated in advisory boards and received honoraria from Abbott Laboratories.

Patient consent for publication Not applicable.

Ethics approval An institutional review board approved the current study protocol and concluded that informed consent was not required (reference number Pro00039954). This method of anonymized data collection and analysis without consent is considered ethical. Human participants were not enrolled in the current study, which used retrospective, anonymized data collected from medical records.

Provenance and peer review Not commissioned; externally peer reviewed.

Data availability statement Data are available on reasonable request. The datasets generated during and/or analyzed in the current study are available from the corresponding author on reasonable request.

Supplemental material This content has been supplied by the author(s). It has not been vetted by BMJ Publishing Group Limited (BMJ) and may not have been peer-reviewed. Any opinions or recommendations discussed are solely those of the author(s) and are not endorsed by BMJ. BMJ disclaims all liability and responsibility arising from any reliance placed on the content. Where the content includes any translated material, BMJ does not warrant the accuracy and reliability of the translations (including but not limited to local regulations, clinical guidelines, terminology, drug names and drug dosages), and is not responsible for any error and/or omissions arising from translation and adaptation or otherwise.

Open access This is an open access article distributed in accordance with the Creative Commons Attribution Non Commercial (CC BY-NC 4.0) license, which permits others to distribute, remix, adapt, build upon this work non-commercially, and license their derivative works on different terms, provided the original work is properly cited, appropriate credit is given, any changes made indicated, and the use is non-commercial. See: http://creativecommons.org/licenses/by-nc/4.0/.

\section{REFERENCES}

1 American Diabetes Association. 6. Glycemic Targets: Standards of Medical Care in Diabetes-2020. Diabetes Care 2020;43:S66-76.

2 American Diabetes Association. 7. Diabetes Technology: Standards of Medical Care in Diabetes-2020. Diabetes Care 2020;43:S77-88.

3 Haak T, Hanaire H, Ajjan R. Flash glucose-sensing technology as a replacement for blood glucose monitoring for the management of insulin-treated type 2 diabetes: a multicenter, open-label randomized controlled trial. Diabetes Ther 2017;8:573-86.

4 Beck RW, Riddlesworth TD, Ruedy K, et al. Continuous glucose monitoring versus usual care in patients with type 2 diabetes receiving multiple daily insulin injections: a randomized trial. Ann Intern Med 2017;167:365.

5 Yaron M, Roitman E, Aharon-Hananel G, et al. Effect of flash glucose monitoring technology on glycemic control and treatment satisfaction in patients with type 2 diabetes. Diabetes Care 2019;42:1178-84.

6 Kröger J, Fasching P, Hanaire H. Three European Retrospective Real-World Chart Review Studies to Determine the Effectiveness of Flash Glucose Monitoring on HbA1c in Adults with Type 2 Diabetes. Diabetes Ther 2020;11:279-91.

7 Vigersky RA, Fonda SJ, Chellappa M, et al. Short- and long-term effects of real-time continuous glucose monitoring in patients with type 2 diabetes. Diabetes Care 2012;35:32-8.

8 Wright EE, Kerr MSD, Reyes IJ, et al. Use of flash continuous glucose monitoring is associated with $\mathrm{A} 1 \mathrm{c}$ reduction in people with type 2 diabetes treated with basal insulin or Noninsulin therapy. Diabetes Spectr 2021;34:184-9.

9 Miller E, Brandner L, Wright E. 84-LB: HbA1c reduction after initiation of the FreeStyle Libre system in type 2 diabetes patients on long-acting insulin or Noninsulin therapy. Diabetes 2020;69:84LB.

10 Elliott T, Beca S, Beharry R, et al. The impact of flash glucose monitoring on glycated hemoglobin in type 2 diabetes managed with basal insulin in Canada: a retrospective real-world chart review study. Diab Vasc Dis Res 2021;18:147916412110213.

11 Martens T, Beck RW, Bailey R, et al. Effect of continuous glucose monitoring on glycemic control in patients with type 2 diabetes treated with basal insulin: a randomized clinical trial. JAMA 2021;325:2262-72.

12 Abbott diabetes care. data on file 2015 .

13 Higgins JPT, Thompson SG, Deeks JJ, et al. Measuring inconsistency in meta-analyses. BMJ 2003;327:557-60.

14 Evans M, Welsh Z, Ells S, et al. The impact of flash glucose monitoring on glycaemic control as measured by HbA1c: a metaanalysis of clinical trials and real-world observational studies. Diabetes Ther 2020;11:83-95.

15 Castellana M, Parisi C, Di Molfetta S, et al. Efficacy and safety of flash glucose monitoring in patients with type 1 and type 2 diabetes: a systematic review and meta-analysis. BMJ Open Diabetes Res Care 2020;8:e001092.

16 Montvida O, Shaw J, Atherton JJ, et al. Long-Term trends in Antidiabetes drug usage in the U.S.: real-world evidence in patients newly diagnosed with type 2 diabetes. Diabetes Care 2018;41:69-78.

17 Ida S, Kaneko R, Murata K. Utility of real-time and retrospective continuous glucose monitoring in patients with type 2 diabetes mellitus: a meta-analysis of randomized controlled trials. J Diabetes Res 2019;2019:1-10.

18 American Diabetes Association. 9. Pharmacologic Approaches to Glycemic Treatment: Standards of Medical Care in Diabetes-2021. Diabetes Care 2021;44:S111-24.

19 Zelnick LR, Weiss NS, Kestenbaum BR, et al. Diabetes and CKD in the United States population, 2009-2014. Clin J Am Soc Nephrol 2017; 12:1984-90.

20 Ilany J, Bhandari H, Nabriski D, et al. Effect of prandial treatment timing adjustment, based on continuous glucose monitoring, in patients with type 2 diabetes uncontrolled with once-daily basal insulin: a randomized, phase IV study. Diabetes Obes Metab 2018;20:1186-92.

21 Ray KK, Kendall DM, Zhao Z, et al. A multinational observational study assessing insulin use: understanding the determinants associated with progression of therapy. Diabetes Obes Metab 2019;21:1101-10.

22 Blonde L, Meneghini L, Peng XV, et al. Probability of achieving glycemic control with basal insulin in patients with type 2 diabetes in real-world practice in the USA. Diabetes Ther 2018:9:1347-58.

23 Blonde L, Aschner P, Bailey C. Global partnership for effective diabetes management. gaps and barriers in the control of blood glucose in people with type 2 diabetes. Diab Vasc Dis Res 2017;14:172-83.

24 Khunti K, Nikolajsen A, Thorsted BL, et al. Clinical inertia with regard to intensifying therapy in people with type 2 diabetes treated with basal insulin. Diabetes Obes Metab 2016;18:401-9.

25 Centers for Disease Control and Prevention (CDC). Prevalence of overweight and obesity among adults with diagnosed diabetes-United States, 1988-1994 and 1999-2002. MMWR Morb Mortal Wkly Rep 2004;53:1066-8. 
26 Centers for Disease Control and Prevention (CDC). National diabetes statistics report 2020. estimates of diabetes and its burden in the United States. Available: https://www.cdc.gov/diabetes/pdfs/data/statistics/ national-diabetes-statistics-report.pdf [Accessed 25th Nov 2020].

27 Ajjan RA, Jackson N, Thomson SA. Reduction in HbA1c using professional flash glucose monitoring in insulin-treated type 2 diabetes patients managed in primary and secondary care settings: a pilot, multicentre, randomised controlled trial. Diab Vasc Dis Res 2019;16:385-95.

28 Monnier L, Colette C, Dejager S, et al. "Mild dysglycemia" in type 2 diabetes: to be neglected or not? J Diabetes Complications 2015;29:451-8. 